\title{
Hemoptysis in a serum ANCA-positive elderly patient
}

\author{
Hiroko WATANABE ${ }^{1}$ \\ Tomohiro TAMURA ${ }^{1}$ \\ Hiroaki SATOH ${ }^{1}$
}

\footnotetext{
1 Division of Respiratory, Mito Medical Center, Tsukuba University, Mito, Japan

1 Tsukuba Üniversitesi Mito Tıp Merkezi, Solunum Bölümü, Mito, Japonya
}

An 81-year-old male patient brought to the emergency clinic in our hospital due to severe dyspnea and hemoptysis. Deteriorated respiratory condition with unknown duration was detected in the patient, who was admitted to the emergency intensive care unit with the primary diagnosis of acute respiratory failure due to unknown cause. His vital findings were as follows: pulse rate, 114 beats per minutes; blood pressure, 156/100 $\mathrm{mmHg}$; respiratory rate, 36 breaths per minute; temperature $37.8 \mathrm{C}$; and oxygen saturation measured by pulse oximetry, $75 \%$. Chest CT scan showed diffuse ground glass opacity in both lungs. The patient was monitored and catheterized. Fiberoptic bronchoscopy (FB) performed so as to observe tracheobronchial appearance and obtain bronchoalveolar lavage fluid. On FB, hyperemic and edematous change was observed at both main bronchi. BAL in the left lower lobe of the lung revealed pulmonary hemorrhage containing hemosiderin-laden macrophages. With corticosteroid and antibiotics, diffuse ground glass opacity in both lungs was disappeared in chest CT scan, which was performed at the seventh hospital day. A few days later, myeloperoxidase anti-neutrophil cytoplasmic antibody (MPO-ANCA) obtained at the time of admission proved to be positive. The patient was discharged home with corticosteroid, which tapered to $5 \mathrm{mg}$ prednisolone daily. The patient is still well without any recurrence of pulmonary hemorrhage for 2 years.

The oldest patient with ANCA-related disease was 86-yearold woman, but she was died from the disease (1). Our patient, to our best knowledge, was the oldest patient with serum ANCA-positive, whose alveolar hemorrhage was successfully treated. Diagnosis of ANCA-related disease must require pathological confirmation of vasculitis $(2,3)$. Hemoptysis may develop in patients with ANCA-positive patient even in the elderly. Therefore, measurement of ANCA must be performed to differentiate ANCA-positive disease.

\section{REFERENCES}

1. Nakamura C, Yorioka N, Nakanishi S, Naito T, Sugimoto N, Kanahara K, et al. Myeloperoxidase antineutrophil cytoplasmic autoantibody-associated glomerulonephritis in a very elderly patient with generalized vasculitis at autopsy. Hiroshima J Med Sci 1997;46:99-104.

2. Lionaki S, Blyth ER, Hogan SL, Hu Y, Senior BA, Jennette CE, et al. Classification of antineutrophil cytoplasmic autoantibody vasculitides: the role of antineutrophil cytoplasmic autoantibody specificity for myeloperoxidase or proteinase 3 in disease recognition and prognosis. Arthritis Rheum 2012;64:3452-62.

3. Watts RA, Mahr A, Mohammad AJ, Gatenby P, Basu N, FloresSuárez LF. Classification, epidemiology and clinical subgrouping of antineutrophil cytoplasmic antibody (ANCA)-associated vasculitis. Nephrol Dial Transplant 2015;30(Suppl 1):i14-22.

\section{Yazışma Adresi (Address for Correspondence)}

Dr. Hiroaki SATOH

University of Tsukuba, Division of Respiratory Medicine, Mito Medical Center, MITO - JAPAN

e-mail: hirosato@md.tsukuba.ac.jp 